\title{
Angka Kejadian Depresi Pada Pasien Hemodialisis Menggunakan Metode Pengukuran Back Depression Inventory
}

\section{Prevalence of Depression in Hemodialysis Patient Evaluated Using Beck Depression Inventory}

\author{
Sarah Musthafa, Linda Armelia \\ Faculty of Medicine, YARSI University, Jakarta \\ Jalan Letjen. Suprapto, Cempaka Putih, Jakarta 10510 \\ Telephone. 021-4206674, 4206675, 4206676 \\ Correspondence: linda.armelia@yarsi.ac.id
}

\begin{abstract}
Abstrak
Latar Belakang: Depresi adalah masalah kejiwaan yang umum terjadi pada pasien penyakit ginjal kronis terutama yang sudah menjalani hemodialysis maupun belum. Tujuan: Penelitian ini bertujuan untuk mengetahui angka kejadian depresi pada pasien penyakit ginjal kronis yang menjalani hemodialisis mengunakan metode pengukuran Beck Depression Inventory di RS Anna Medika, Bekasi. Metode: Penelitian ini dilakukan secara deskripsi cross sectional. Penelitian dilakukan pada pasien penyakit ginjal kronik yang sedang menjalani hemodialisis di RS Anna Medika Bekasi. Hasil: Dari 156 pasien yang ikut penelitian didapatkan 82 (52,6\%) depresi minimal, 37 $(23,7 \%)$ depresi sedang, $24(15,4 \%)$ depresi berat dan $13(8,3 \%)$ depresi sangat berat. Simpulan: Penelitian ini menunjukan bahwa depresi yang paling banyak dialami adalah tipe depresi minimal, walaupun tidak mengabaikan depresi sangat berat yang juga dialami. Saran: Bagi para tenaga kesehatan diharapkan dapat membantu pasien terutama dalam menangani masalah psikologis khususnya depresi. Selain itu, keluarga pasien dianjurkan agar dapat memberikan perhatian lebih dan menjadi life support system untuk kemajuan dan kelangsungan hidup pasien.
\end{abstract}

Kata Kunci: Depresi, Penyakit Ginjal Kronis, Hemodialisis

\section{Abstract}

Background: Depression is the most common psychological problem that occurs among patients with chronic kidney disease especially in hemodyalisis patients. Objective: This study aims to determine the prevalence of depression in hemodialysis patient evaluated using beck depression inventory measurement method at Anna Medika Hospital, Bekasi. Method: This study was conducted using a descriptive cross sectional study. The subjects of the study were chronic kidney disease patients who were undergoing hemodialysis at Anna Medika Hospital Bekasi. Results: From 156 patiets, the results showed that 82 (52.6\%) were having minimal depression, 37 (23.7\%) mild depression, 24 (15.4\%) moderate depression and 13 (8,3\%) severe depression. Conclusion: Research showed that minimal depression is the most common depression in the patients followed by 
mild, moderate and severe depression. Suggestion: Health workers are expected to be able to help patients in dealing with psychological problems, especially depression. Moreover, patients' families are encouraged to give more attention to the patient and provide life support system for the progress and survival of patients.

Keywords: Depression, Chronic Kidney Disease, Hemodialysis

\section{Pendahuluan}

Depresi merupakan keadaan mental dengan suasana hati yang terganggu ditandai perasaan sedih, keputusasaan atau berkecil hati. ${ }^{1}$ Depresi merupakan masalah kejiwaan paling umum terjadi pada pasien penyakit ginjal kronis (PGK). Kondisi gagal ginjal yang diikuti dengan hemodialisis (HD) merupakan kondisi yang sangat tidak nyaman. Kenyataan bahwa pasien gagal ginjal terutama PGK yang tidak bisa lepas dari HD sepanjang hidupnya menimbulkan dampak psikologis yang tidak sedikit. ${ }^{2}$ Prevalensi depresi pasien PGK yang menjalani HD bervariasi dari $22.8 \%$ (diagnosisberbasis wawancara) sampai dengan $39.3 \%$ (penilaian diri sendiri atau dengan penilaian klinisi). ${ }^{3}$ Walaupun kasus depresi pada pasien PGK memiliki prevalensi yang cukup tinggi, kasus ini belum banyak mendapat perhatian dan intervensi untuk meningkatkan kesehatan psikologis pasien. Pada penelitian ini digunakan kuisioner Beck Depression Inventory (BDI). BDIII terdiri dari 21 topik untuk menilai intensitas depresi pada orang sehat maupun sakit secara fisik. Setiap topik terdiri dari empat pernyataan yang mengindikasikan gejala depresi tertentu. Penelitian ini juga membahas mengenai hubungan depresi dengan ketaatan beragama. Hasil penelitian diharapkan dapat membantu tenaga kesehatan dan keluarga untuk meningkatkan pemahaman mengenai depresi pada pasien PGK serta dalam meningkatkan kesehatan psikologis pasien.

\section{Metode}

Penelitian ini dilakukan secara deskriptif cross sectional yang bertujuan untuk mengetahui angka kejadian depresi pada pasien PGK yang sedang menjalani HD. Sampel penelitian ditentukan dengan cara consecutive sampling berjumlah 156 orang di Rumah Sakit Anna Medika Bekasi. Data yang diperoleh dianalisis menggunakan Statistical Package for Social Science (SPSS).

\section{Hasil}

Penelitian hubungan lama hemodialisis dengan kejadian depresi ini dilakukan pada pasien PGK yang menjalani HD di RS Anna Medika Bekasi sebanyak 156 orang. Distribusi sampel berdasarkan jenis kelamin didapatkan laki-laki sebanyak 87 (55,8\%) dan perempuan $69(44,2 \%)$. Distribusi sampel berdasarkan kelompok usia $<40$ tahun sejumlah 14 (8,9\%), kelompok usia 40 - 50 tahun 48 (30.8\%) dan usia $>50$ tahun 94 (60.3\%). Berdasarkan lama menjalani HD didapatkan hasil HD $<12$ bulan 69 (44,3\%), HD 12-24 bulan 35 (22,4\%), 25-36 bulan $13(8,3 \%)$ dan $>36$ bulan 39 (25\%). Berdasarkan ketaatan beragama didapatkan 148 (94,9\%) memiliki tingkat ketaatan beragama yang sangat taat, $8(5,1 \%)$ taat sedangkan untuk cukup taat dan kurang taat tidak ada (table 1) 
Tabel 1. Karakteristik Demografi Pasien

\begin{tabular}{lc}
\hline \multicolumn{1}{c}{ Karakteristik } & $\begin{array}{c}\text { Jumlah }(\mathrm{n}) / \\
\text { Persentase }(\%)\end{array}$ \\
\hline $\begin{array}{l}\text { Jenis kelamin } \\
\text { Laki-laki }\end{array}$ & $87(55.8)$ \\
$\quad$ Perempuan & $69(44.2)$ \\
Kelompok usia (tahun) & \\
$<40$ & $14(8.9)$ \\
$40-50$ & $48(30.8)$ \\
$>50$ & $94(60.3)$ \\
& \\
Lama hemodialysis (bulan) & \\
$<12$ & $69(44.3)$ \\
$12-24$ & $35(22.4)$ \\
$25-36$ & $13(8.3)$ \\
$>36$ & $39(25)$ \\
& \\
Ketaatan terhadap agama & $148(94.9)$ \\
Sangat taat & $8(5.1)$ \\
Taat & 0 \\
Cukup taat & 0 \\
Kurang taat & \\
\hline
\end{tabular}

Tabel 2. Angka Kejadian Depresi Pada Pasien Penyakit Ginjal Kronis Yang Menjalani Hemodialis Dengan Metode Pengukuran Beck Depression Inventory

\begin{tabular}{lc}
\hline \multicolumn{1}{c}{ Tingkat depresi } & $\begin{array}{c}\text { Jumlah }(\mathrm{n}) / \\
\text { Persentase (\%) }\end{array}$ \\
\hline Minimal & $82(52.6)$ \\
Sedang & $37(23.7)$ \\
Berat & $24(15.4)$ \\
Sangat berat & $13(8.3)$ \\
\hline
\end{tabular}

Pengukuran angka kejadian depresi dengan menggunakan metode Beck depression Invertory didapatkan hasil sebanyak $82(52,6 \%)$ depresi minimal, 37 (23,7\%) depresi sedang, 24 $(15,4 \%)$ depresi berat dan $13(8,3 \%)$ depresi sangat berat sebanyak (table 2).

Angka kejadian depresi dihubungan dengan kelompok umur didaptakan usia $<40$ tahun $14(8,9 \%)$ mengalami depresi dengan perincian 6 (3,9\%) depresi minimal, 3 (1,9\%) depresi sedang, $4(2,6 \%)$ depresi berat dan 1 $(0,5 \%)$ depresi sangat berat. Kelompok usia 4050 tahun 48 (30,8\%) dengan rincian 27 (17,3\%) depresi minimal, $8(5,1 \%)$ depresi sedang, 7 $(4,5 \%)$ depresi berat serta $6(3,9 \%)$ depresi sangat berat. Kelompok usia $>50$ tahun ada 94 $(60,3 \%)$ dengan pembagian $49(31,4 \%)$ depresi minimal, 26 (16,7\%) depresi sedang, 13 (8,3\%) depresi berat dan $6(3,9 \%)$ depresi sangat berat. Angka kejadian depresi pada laki-laki sebanyak 87 (55,8\%) dimana 43 (27,6\%) depresi minimal, 23 (14,8\%) depresi sedang, 14 $(8,9 \%)$ depresi berat dan $7(4,5 \%)$ depresi sangat berat. Pada perempuan 69 (44,2\%) mengalami depresi, dengan perincian 39 (25\%) depresi minimal, 14 (8,9\%) depresi sedang, 10 (6.4\%) depresi berat dan 6 (3.9\%) depresi sangat berat. 10 orang $(6,4 \%)$ depresi berat dan 6 orang $(3,9 \%)$ mengalami depresi sangat berat.

Sementara hubungan dengan lama HD, $<12$ bulan $69 \quad(44,2 \%)$ mengalami depresi dengan perincian 39 (25\%) depresi minimal, 15 $(9,6 \%)$ depresi sedang, 10 (6,4\%) depresi berat dan $5(3,2 \%)$ depresi sangat berat. Pada kelompok HD 12- 24 bulan didapatkan 35 $(22,4 \%)$ mengalami depresi dengan perincian $17(10,8 \%)$ depresi minimal, $8(5,1 \%)$ depresi sedang, 7 orang $(4,5 \%)$ depresi berat dan 3 $(1,9 \%)$ depresi sangat berat. Pada kelompok yang menjalani HD 25-36 bulan didapatkan hasil $13(8,3 \%)$ mengalami depresi dengan perincian 6 (3,9\%) depresi minimal, 3 (1,9\%) depresi sedang, $2(1,3 \%)$ depresi berat dan 2 $(1,3 \%)$ depresi sangat berat. Pasien yang menjalani HD $>36$ bulan yang mengalami depresi berjumlah 39 (25\%) dengan rincian, 20 $(12,8 \%)$ depresi minimal, 11 (7\%) depresi 
sedang, $5(3,2 \%)$ depresi berat dan $3(1,9 \%) \quad$ depresi sangat berat (table 3$)$.

Tabel 3. Angka Kejadian Depresi Berdasarkan Kelompok Usia, Jenis Kelamin dan Lama Hemodialisis

\begin{tabular}{|c|c|c|c|c|c|}
\hline \multirow[t]{2}{*}{ Karakteristik } & \multicolumn{4}{|c|}{ Tingkat Depresi (n/\%) } & \multirow[t]{2}{*}{ Jumlah (n/\%) } \\
\hline & Minimal & Sedang & Berat & Sangat Berat & \\
\hline \multicolumn{6}{|l|}{ Kelompok usia (tahun) } \\
\hline$<40$. & $6(3.9)$ & $3(1.9)$ & $4(2.6)$ & $1(0.5)$ & $14(8.9)$ \\
\hline $40-50$ & $27(17.3)$ & $8(5.1)$ & $7(4.5)$ & $6(3.9)$ & $48(30.8)$ \\
\hline$>50$ & 49 (31.4) & $26(16.7)$ & $13(8.3)$ & $6(3.9)$ & $94(60.3)$ \\
\hline \multicolumn{6}{|l|}{ Jenis kelamin } \\
\hline Laki-laki & $43(27.6)$ & $23(14.8)$ & $14(8.9)$ & $7(4.5)$ & $87(55.8)$ \\
\hline Perempuan & $39(25)$ & $14(8.9)$ & $10(6.4)$ & $6(3.9)$ & $69(44.2)$ \\
\hline \multicolumn{6}{|l|}{ Lama HD (bulan) } \\
\hline$<12$ & $39(25)$ & $15(9.6)$ & $10(6.4)$ & $5(3.2)$ & $69(44.2)$ \\
\hline $12-24$ & $17(10.8)$ & $8(5.1)$ & $7(4.5)$ & $3(1.9)$ & $35(22.4)$ \\
\hline $25-36$ & $6(3.9)$ & $3(1.9)$ & $2(1.3)$ & $2(1.3)$ & $13(8.3)$ \\
\hline$>36$ & $20(12.8)$ & $11(7)$ & $5(3.2)$ & $3(1.9)$ & $39(25)$ \\
\hline \multicolumn{6}{|l|}{$\begin{array}{l}\text { Tingkat ketaatan } \\
\text { beragama }\end{array}$} \\
\hline Sangat taat & $78(52.7)$ & $36(24.3)$ & 22 & 12 & $148(94.9)$ \\
\hline Taat & $4(50)$ & $1(12.5)$ & 2 925) & $1(12.5)$ & $8(5.1)$ \\
\hline Cukup taat & 0 & 0 & 0 & 0 & 0 \\
\hline Kurang taat & 0 & 0 & 0 & 0 & 0 \\
\hline
\end{tabular}

Tabel 4. Angka Kejadian depresi dan ketaatan beragama

\begin{tabular}{lccccc}
\hline \multicolumn{1}{c}{ Karakteristik } & \multicolumn{2}{c}{ Tingkat Depresi (n/\%) } & & Jumlah (n/\%) \\
& Minimal & Sedang & Berat & Sangat Berat & \\
\hline $\begin{array}{l}\text { Tingkat ketaatan } \\
\text { beragama }\end{array}$ & & & & & \\
$\quad$ Sangat taat & 78 & 36 & 22 & 12 & $148(94.9)$ \\
$\quad$ Taat & 4 & 1 & 2 & 1 & 8 (5.1) \\
Cukup taat & 0 & 0 & 0 & 0 & 0 \\
$\quad$ Kurang taat & 0 & 0 & 0 & 0 & 0 \\
\hline
\end{tabular}

Sementara untuk hubungan antara depresi dengan ketaatan beragama (tabel 4), tidak ada hubungan antara ketaatan agama dengan angka kejadian depresi pada pasien PGK yang menjalani HD $(p>0,05)$.

\section{Diskusi}

Pada penelitian ini didapatkan sebanyak $82(52,6 \%)$ depresi minimal, 37 $(23,7 \%)$ depresi sedang, $24(15,4 \%)$ depresi berat dan $13(8,3 \%)$ depresi sangat berat. Depresi sendiri akan memicu gejala perasaan subjektif mengenai kesedihan, perasaan kehilangan harapan dan putus asa yang terus menerus atau sindrom klinis munculnya 
gangguan depresi disertai dengan beberapa gejala tambahan, seperti keletihan, kehilangan energi, kesulitan tidur dan perubahan pola makan (Emery et al., 2000). Depresi minimal merupakan tingkat depresi yang paling banyak dialami oleh pasien, lalu dikuti dengan depresi sedang, depresi berat dan depresi sangat berat menempati posisi terakhir. Hasil ini sesuai dengan penelitian Cengic yang menunjukan $30 \%$ pasien mengalami depresi ringan (Čengić, Badema, Resić, Halima. 2010).

Depresi pada pasien PGK yang menjalani HD disebabkan faktor yang berhubungan dengan kehidupan sosial, psikologis dan mekanisme biologi. Faktor kehilangan sesuatu yang sebelumnya ada seperti kebebasan, pekerjaan dan kemandirian adalah hal-hal yang sangat dirasakan oleh para pasien gagal ginjal yang menjalani HD.

Angka kejadian depresi pada kelompok usia paling banyak ditemukan pada kelompok usia >50 tahun sebesar $60,3 \%$, dilanjutkan dengan kelompok usia 40-50 tahun sebesar $30,8 \%$ dan kelompok usia $<40$ tahun sebesar $8,9 \%$. Depresi lebih banyak terjadi pada kelompok usia yang lebih tua karena adanya faktor penurunan kemampuan fisik dan intelektual yang akan mengurangi kemandirian pasien. Sementara depresi yang terjadi pada kelompok usia yang lebih muda dikarenakan adanya keterbatasan dalam melakukan aktifitas serta keharusan untuk berobat seumur hidup sehingga memberi tekanan tersendiri bagi pasien.

Pada distribusi angka kejadian depresi berdasarkan jenis kelamin diketahui bahwa angka kejadian depresi pada laki - laki lebih tinggi dari perempuan yaitu sebesar 55,8\%, disebabkan karena penurunan kemampuan fisik dan keharusan untuk berobat seumur hidup yang akan mempengaruhi kemampuan pasien untuk bekerja dan bersosialisasi. Akan tetapi hasil yang didapat dalam penelitian ini bisa saja terjadi dikarenakan responden laki-laki lebih banyak dibandingkan responden perempuan.

Distribusi angka kejadian depresi berdasarkan lama menjalani HD menunjukan bahwa kejadian depresi terbanyak terdapat pada pasien dengan lama HD $<12$ bulan dengan persentase $44,2 \%$. Pasien yang telah menjalani HD $>12$ bulan biasanya sudah bisa menerima keadaan atau sudah berada dalam fase acceptance dan sudah beradaptasi dengan alat maupun keharusan untuk melakukan HD. Sementara pada pasien yang belum lama melakukan HD pasien ini masih mengalami fase rejection dan belum bisa untuk menerima kenyataan. Pasien yang menjani HD $>12$ bulan mengalami depresi karena adanya rasa bosan, dan kenyataan bahwa harus menjalani HD seumur hidup, penurunan kemampuan fisik yang nyata juga berbagai faktor lainnya seperti ekonomi dan sosial.

Penelitian ini juga membahas bagaimana hubungan antara ketaatan agama dengan angka kejadian depresi dimana tidak ada hubungan antara ketaatan agama dan angka kejadian depresi $(p>0,05)$. Hal ini disebabkan karena pertanyaan kuisioner bersifat mendasar dan kurang mendalam sehingga tidak dapat menjawab mengenai hubungan tingkat depresi dengan kepatuhan agama. Sejatinya ketaatan kepada tuhan tidak dapat diukur hanya dengan beberapa pertanyaan. Untuk hasil yang lebih akurat dibutuhkan penelitian yang lebih rinci dan mendalam terhadap masalah ini.

Skoring BDI-II dalam suatu penelitian bisa saja berbeda dengan penelitian lainnya, dikarenakan depresi tingkat minimal dalam BDI 
- II masih dianggap sebagai suatu kondisi normal, apabila jumlah nilai skoring BDI-II >14 atau dalam penelitian ini depresi tingkat sedang barulah kondisi ini memerlukan pemeriksaan dan tindakan lebih lanjut. Dalam penelitian yang dilakukan oleh Cengic $^{5}$ dan Rustina ${ }^{7}$ skoring depresi ringan atau minimal dimulai dengan jumlah nilai $>14$ atau dalam penelitian ini depresi tingkat sedang. Akan tetapi perbedaan ini bukanlah suatu masalah karena hasil penelitian yang didapatkan juga tidak jauh berbeda dan penelitian ini dilakukan untuk mengetahui angka kejadian depresi pada pasien PGK yang menjalani HD yang ditujukan sebagai salah satu bentuk early screening depresi pada pasien.

\section{Simpulan}

Penelitian pada 156 pasien yang menjalani HD di RS Anna Medika Bekasi menunjukan angka kejadian depresi minimal 82 (52,6\%), depresi sedang 37 (23,7\%), depresi berat $24(15,4 \%)$ dan depresi sangat berat 13 $(8,3 \%)$. Depresi pada kelompok usia paling banyak terjadi pada kelompok usia $>50$ tahun sebesar $60,3 \%$, untuk kejadian depresi pada laki - laki lebih tinggi dari perempuan yaitu sebesar 55,8\% dan kejadian depresi terbanyak terdapat pada pasien dengan lama HD $<12$ bulan dengan persentase $44,2 \%$. Tidak didapatkan adanya hubungan antara angka kejadian depresi pada pasien dengan ketaatan terhadap agama.

\section{Saran}

Bagi para tenaga kesehatan diharapkan dapat lebih memahami mengenai depresi pada pasien PGK yang menjalani HD dan melakukan early screening depresi untuk dapat membantu pasien dalam menangani masalah depresi. Pada keluarga pasien agar dapat memberikan perhatian lebih kepada pasien yang sedang menjalani hemodialisis dan menjadi life support system untuk kemajuan dan kelangsungan hidup pasien. Depresi dan PGK adalah penyakit yang dianjurkan untuk berobat karena Allah menurunkan penyakit dan obatnya. Sebagaimana sabda Rasulullah SAW "Setiap penyakit ada obatnya. Jika obat yang tepat diberikan, dengan izin Allah, penyakit itu akan sembuh" (HR Ahmad dan Hakim).

\section{Daftar Pustaka}

Amalia, Fitri, Nadjmir, Azmi, Syaiful. 2015. Gambaran Tingkat Depresi pada Pasien Penyakit Ginjal Kronik yang Menjalani Hemodialisis di RSUP DR. M. Djamil Padang. Padang: Universitas Andalas

American Psychological Association (APA). 2010. Publication Manual of the American Psychological Association. Ed 6. Washington, DC: American Psychological Association

Andri. 2013. Gangguan Psikiatrik pada Pasien Penyakit Ginjal Kronik. Jakarta:KalbeMed

Awwa, Izzat Ahmad, Jallad, Shatha Ghalib. 2017. Prevalence of Depression in Jordanian Hemodialysis Patients. Iran: Iranian Journal of Psychiatry and Behavioral Sciences.

Beck, A.T., Ward, C. H., Mendelson, M., Mock, J., \& Erbaugh, J. 1961. An inventory for measuring depression. Archives of General Psychiatry. Philadelphia: University of Pensylvania.

Čengić, Badema, Resić, Halima. 2010. Depression in Hemodialysis Patients. Bosnia: Bosnian Journal of Basic Medical Sciences

Cukor, Daniel,Coplan, Jeremy, Brown, Clinton, Friedman, Steven, Cromwell-Smith, 
Allyson, Peterson, Rolf A, Kimmel, Paul

L. 2007. Depression and Anxiety in Urban

Hemodialysis Patients. New York:

American Society of Nephrology.

Dorland, W.N, 2015. Kamus Saku Kedokteran Dorland. Ed 29. Jakarta:Elsevier.

Emery, et al. 2000. Cognitive therapy of depression. New York: The Guilford Press.

Jung, Sang, et al. 2012. Relationship between Cognitive Impairment and Depression in Dialysis Patients. Korea:Yonsei Med J

Lopes, A., Albert, J., Young, E., Satayathum, S., Pisoni, R., \& Andreucci, V. 2004. Screening for depression in hemodialysis patients: Associations with diagnosis, treatment, and outcomes in the DOPPS.
Ann Arbor: International Society of Nephrology

Phillip K.T Li. 2016. Depression in Dialysis Patients. Hongkong: University of Hongkong.

Rustina, Et Al. 2012. Gambaran Tingkat Depresi Pada Pasien Gagal Ginjal Kronik Yang Menjalani Hemodialisis di RSUD dr. Soedarso Pontianak Tahun 2012. Pontianak: Universitas Tanjungpura.

Sadock BJ, Sadock VA. 2007. Kaplan \& Sadock's Comprehensive Textbook of Psychiatry. Ed 9. Philadelphia: Lippincott Williams \& Wilkins.

Wijaya, A. 2005. Kualitas hidup pasien penyakit ginjal kronik yang menjalani hemodialisis dan mengalami depresi. Jakarta: Universitas Indonesia. 